Ankara Ecz. Fak. Der.

15, 91 (1985)
J. Fac. Pharm. Ankara

15, 91 (1985)

\title{
Solatium dulcamara L. Yapraklari Üzerinde Kimyasal Bir Çalışma
}

A chemical study on the leaves of Solanum dulcamara L.

Engin ŞARER*

\author{
Turhan ÇAKIROĞLU*
}

ÖZET

Bu çalışmada kültüre alınmış Solanum dulcamara L. bitkisinin yapraklarında bulunan steroidal alkaloitler incelenmiştir. İ́ce tabaka kromatografisi yöntemiyle yaprakların 2 glukoalkaloit içerdiği saptanmış, ancak glukoalkaloitlerin hidrolizinden sonra yapılan İTK analizinde bu glukoalkaloitlerin aynı alkaminden türediği anlaşılmıştır. Alkamin izole edilerek E.N. tayin edilmiş, IR, UV ve kütle spektroskopisi yöntemleri ile yapısı aydınlatılmış ve solasodin olduğu belirlenmiştir.

\section{SUMMARY}

In this research, steroidal alkaloids in the leaves of cultivated Solanum dulcamara $L$. were investigated.

By thin-layer chromatography was found that the leaves contain 2 glycoalkaloids, but by the thin-layer analysis after the hydrolysis of glycoalkaloids was shown that both glycoalkaloids derived from the same alkamine.

After the isolation of the alkamine its m.p. was determined. The chemical structure of the alkamine was elucidated by its ir, ms and uv analysis and it was confirmed to be solasodine.

Redaksiyona verildiği tarih: 1.8.1985

*Farmakognozi Anabilim Dalı, Eczacılık Fakültesi, Ankara Üniversitesi 
Anahtar kelimeler: Solanum dulcamara L.; Steroidal alkaloit; Solasodin.

Steroidal hormonlar tedavide yaygın olarak kullanılan ilaçlardır. Bu ilaçların endüstriyel üretimi için steroidal sapogenoller çok uygun doğal başlangıç maddeleridir (1). Steroidal hormonların total sentezi kompleks ve pahalı bir işlemdir. Bu nedenle doğal hammadde kaynaklarından yararlanılarak gerçekleştirilen yarı sentez yöntemi, bu maddelerin üretiminde daha verimli bir yoldur. Endüstride steroidal hormon başlangıç maddelerini yüksek oranda içeren bitkilerden yararlanılır. Bu bitkilerden elde edilen steroidal sapogenollerden diosgenin, hekogenin ve bir sterol olan $\beta$-sitosterol ile stigmasterol, steroidal hormon üretiminde kullanılan başlıca hammaddelerdendir. Diosgenin kolaylıkla ve \%75'in üzerinde bir verimle seks hormonları, kontraseptif ilaçlar ve kortikosteroitlerin üretiminde kullanılan pregnadienolon asetat'a dönüşebildiğinden, bu maddenin steroidal hormon yarı sentezinde ayrı bir önemi vardır (2).

Ancak, diosgenin'den hareketle steroidal hammadde üretimi ile dünya gereksinimi karşılanamadı̆̆ından yeni bitkisel kaynaklar araştırılmış ve özellikle sapogenol içeren bitkilerin yetiştirilemediği ülkelerde çalışmalar yeni başlangıç maddelerinin elde edilebileceği bitkiler üzerinde yoğunlaşmıştır. Sonuçta, steroidal alkaloitlerin de hormon yarı sentezinde kullanılabileceği anlaşılmıştır. Halen endüstride hormon üretiminde kullanilan steroidal alkaloit, diosgenin'in azotlu bir analoğu olan solasodin'dir. Solasodin'den hareketle ve diosgenin üzerinde yapılana eşit bir işlemde kolayca steroidal hormonlara geçilebilmektedir.

Ayrıca, yapılan araştırmalar sonucunda tomatidin ve tomatidenol steroidal alkaloitlerinden de hormon yarısentezinde yararlanılabileceği ortaya konmuştur.

Steroidal alkaloitler bitkilerde genellikle glukoalkaloitler (glukozit) halinde, nadiren serbest (alkamin) halde bulunurlar (3, 4, 5).

Solasodin alkamini Soianaceae familyasının Solanum cinsine ait bitkilerde bulunmaktadir. Bu alkaloidin Solanum cinsinin 60'tan fazla türünde ve bu bitkilerin özellikle yapraklarında bulunduğu belirlenmiştir $(5,6,7,8,9,10,11,12)$. Bitkilerin yapraklarındaki solasodin miktarı türlere, genetik faktörlere, iklim ve çevre şartlarına bağlı ola- 
Solanum dulcamara L. Yaprakları Üzerinde Kimyasal Bir.

rak \% 0.1-4.4 arasında değişmektedir $(2,13)$ ve endüstriyel hormon üretimi için bu alkaloidi yüksek oranda içeren (kuru herba üzerinden $\% 0.90-2.80)$ doğal ya da kültüre alınmış Solanum laciniatum ve Solatium avicuiare gibi bitkiler kullanılmaktadır $(2,8)$.

Solanum cinsine ait türlerden 4 tanesi ülkemizde doğal olarak yetişmektedir (14). Bunlar S.dulcamara L., S.luteum Mill., S.alatum Moench, S.nigrum L. dur. Anadolu kaynaklı bu türlerin yaprakları üzerinde günümüze değin yapılmış kimyasal bir çalışma bulunmamaktadır. Bu türler üzerinde yapacağımız çalışmaların başlangıcı olarak kültüre alınmış bir Solanum dulcamara $L$. örneğinin yapraklarındaki steroidal alkaloitleri belirlemek üzere çalışmalar yaptık.

\section{DENEL KISIM}

\section{Materyal:}

Üzerinde araştırma yapılan materyal, A. Ü. Fen Fakültesi Botanik Bahçesinde kültüre alman Solanum dulcamara L.'nın kurutulmuş yapraklaridir.

\section{Metod:}

Materyaldeki steroidal alkaloitleri belirlemek üzere;

- Glukoalkaloitler sicakta etanolle tüketilmiş,

- Glukoalkaloitlerin Silikagel G (Merck) ile kapli plaklarda ince tabaka kromatografisi ile analizi yapılmış,

- Glukoalkaloitlerin hidrolizi ile elde edilen alkaminin ince tabaka kromatografisi ile analizi yapılmış,

- Kristallendirme ile saflaştırılan alkaminin ergime noktası tayin edilip IR, UV ve kütle spektroskopisi yöntemleriyle yapısı aydınlatılmıştır.

Uygulamalar sırasında alkaminin ergime noktası "Electrothermal" ergime noktası tayin cihazında tayin edilmiştir, IR spektrumu "Perkin Elmer 1330 Model Spectrometer" ile, UV spektrumu "Perkin Elmer Lambda 5 Model UV Spectrometer" ile, kütle spektrumu ise "Finnigan Mat 1020 Automated MS Model Spectrometer" ile alınmıştır. 


\section{Glukoalkaloitlerin tüketilmesi:}

Kurutulup toz edilen S.dulcamara L. yaprakları (480g)，\%95 lik etanol ile sıcakta 6 saat süreyle tüketildi (15). Ekstre yoğunlaştırıldıktan sonra \% 2 lik asetik asit ile reçineli maddeler uzaklaştırıldı. Ekstre $70^{\circ} \mathrm{C}$ ye kadar 1sıtılıp, \% 25 lik amonyak çözeltisi ilâvesiyle ham glukoalkaloitler çöktürüldü. Çökelek \% $611 \mathrm{k}$ asetik asitte çözülüp, amonyak çözeltisi ile tekrar çöktürüldü.

Literatür verilerine göre S.dulcamara steroidal saponozit de içermektedir $(16,17)$. Bu nedenle çökeleğe alkaloit ve saponozit testleri uygulandı ve çökeleğe az da olsa saponozit karıştı̆̆ı anlaşıldı. Tekrarlanan çöktürmelerle çökelek saponozitlerden kurtarılmaya çalışıldı.

Glukoalkaloit karışımın ince tabaka kromatografisi ile analizi:

$20 \times 20 \mathrm{~cm}$ boyutlarındaki Silikagel G (Merck) 7731 ile kaplı plaklar $(0.25 \mathrm{~mm})$ üzerinde ve literatürdeki değişik çözücü sistemleri denenerek, glukoalkaloitler analiz edildi $(10,18,19,20,21)$. Bu sistemler arasında en iyi ayırım kloroform: etanol: \% 1 lik amonyak (3:3:1, alt faz) ile gerçekleşti. Uygulama $17^{\circ} \mathrm{C}$ de yapıldı ve plaklar $15 \mathrm{~cm}$ yürütüldü.

Belirteç olarak Dragendorff, \% 50 lik sülfürik asit ve Kaegi - Miescher kullanıldi. Dragendorff belirteci genel alkaloit belirteci olduğundan, sülfürik asit belirteci steroidal alkaloitlerle karakteristik renkler verdiğinden, Kaegi-Miescher belirteci ise steroidal saponozit lerle, steroidal alkaloitlerin ayırdedilmelerini sağlamak amacıyla kullanıldı. Steroidal saponozitler Kaegi-Miescher belirteci ile UV'de floresans vermeyen soluk sarı bir renk, steroidal alkaloitler ise $U^{\prime} V^{\prime}$ e floresans veren ve isıtılmakla pembeden koyu maviye kadar değişen renkler verirler (10) (Krom. 1 ve 2 ).

\section{Glukoalkaloitlerin hidrolizi:}

28 Ham glukoalkaloit karışımı S.dulcamara için literatürde verilen yönteme (17) uyularak, etanol ve \% 10 luk HG1 karışımı ile 3 saat süreyle hidroliz edildi. Sıcak su ilâve edilerek birkaç saat kendi haline bırakıldı. Çöken alkamin hidroklorürleri süzülerek ayrıldı. 


\section{Serbest alkaminin çöktürülmesi:}

Elde edilen alkamin hidroklorür, karışma olasılığı olan sapogenolleri uzaklaştırmak amacıyla sıcak kloroform ile çalkalanarak tüketildi (7). Temizlenen alkamin hidroklorür $\% 80$ lik metanolle tüketilip, \% 25 lik amonyak çözeltisi ile pH: 9-10'a ayarland $1.70^{\circ} \mathrm{C}$ ye kadar 1sıtılıp, sıcak su ilâve edilerek ham alkamin çöktürüldü $(17,22)$.

\section{Alkaminin ince tabaka kromatografisi ile analizi:}

Bu analiz sırasında kloroform: metanol (19:1) çözücü sistemi ve Kaegi-Miescher, \% 50 sülfürik asit belirteçlerinden yararlanıldı. Uygulama $21^{\circ} \mathrm{C}$ de yapıldı ve plaklar $15 \mathrm{~cm}$ yürütüldü.

Sülfürik asit belirteci alkaminler ile karakteristik renkler vererek, yapıları çok yakın olan alkaminlerin ayırdedilmesini sağlayan bir belirteç olması nedeniyle kullanıldı ve plaklar $80-300^{\circ} \mathrm{C}$ arasında 1sitılarak alkamin lekeleri test edildi (23) (Krom. 3 ve 4).

\section{Alkaminin saflaştırılması:}

Alkaminin ince tabaka kromatografisi ile analizinde steroidal sapogenol ve "dien" lekeleri gözlendiği için, alkamini temizlemek üzere su ve metanolden kristallendirildi. Ve elde edilen alkamin kristallerinin ince tabaka plağında verdiği leke, standart solasodininki ile karşılaştırıldı (Krom. 5).

\section{Alkaminin ergime noktasinin tayini:}

Elde edilen alkaminin ergime noktasi 199-200 $\mathrm{C}$ olarak saptandı. Ve bu değer literatür verileriyle karşılaştırıldı.

\section{Alkaminin spektral yöntemlerle analizi:}

Alkaminin kesin tanısını yapmak amacıyla IR, UV, kütle spektroskopisi gibi yöntemlerden yararlanıldı. Ve sonuçlar saf solasodin için bulunan değerlerle (24) karşılaştırıldı.

\section{SONUÇ ve TARTIŞMA}

Solanım dulcamara $L$. yapraklarından izole edilen ham glukoalkaloitierin ( $3.35 \mathrm{~g})$ ince tabaka kromatografisiyle analizi sonucu elde edilen kromatogramlar aşağıda görülmektedir (Krom. 1 ve 2). 
Belirteç olarak \% 50 lik sülfürik asit çözeltisi kullanıldı̆̆ında $\mathrm{Rf},: 0.23$ ve $\mathrm{Rf}_{2}$ : 0.33 de pembe renkli 2 steroidal alkaloit lekesi (Krom.1), Dragendorff belirteci kullanıldı̆̆ında aynı Rf değerlernde turuncu renkli 2 leke, Kaegi-Miescher belirteci kullanıldı̆̆ında ise Rfi: 0.17 de UV'de floresans vermeyen soluk sarı renkli steroidal saponozit, $\mathrm{Rf}_{2}$ : 0.23 ve $\mathrm{Rf}_{3}: 0.33 \mathrm{de}$ ise $\mathrm{UV}^{\prime} \mathrm{de}$ floresans veren mavimsiyeşil renkli steroidal alkaloit lekeleri görülmüştür.

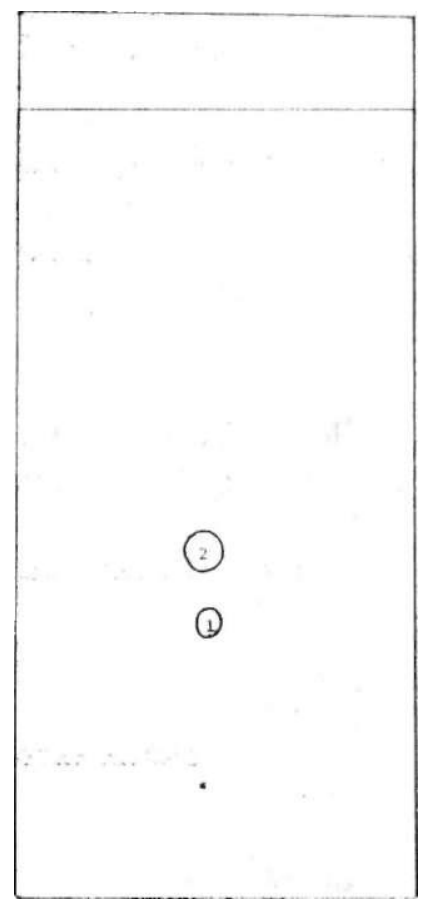

Krom. 1: Glukoalkaloitlerin ince tabaka kromatogramı

Belirteç: \% $50 \quad \mathrm{H}_{2} \mathrm{SO}_{4}$

1 ve 2: glukoalkaloit (pembe)

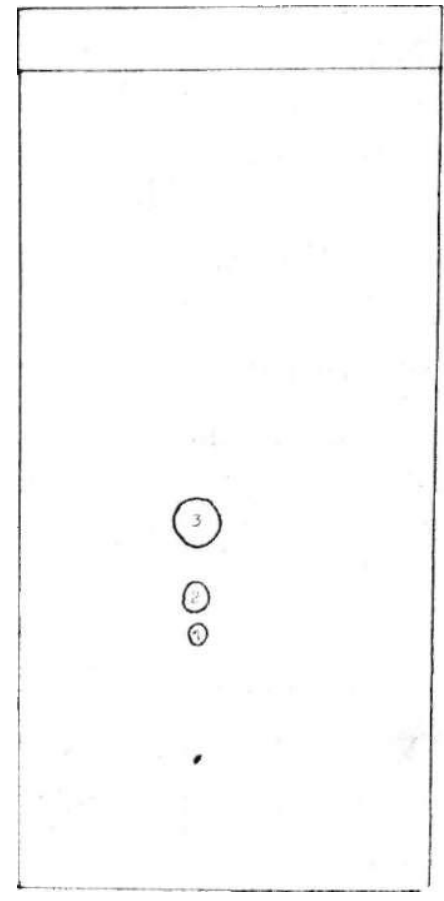

Krom. 2: Glukoalkaloitlerin ince tabaka kromatogramı

Belirteç: Kaegi-Miescher

1: Steroidal saponozit (soluk sarı)

2 ve 3: Glukoalkaloit

(mavimsi-yeşil)

Glukoalkaloitlerin hidrolizi sonucunda elde edilen alkaminin (2 g ham glukoalkaloitten $330 \mathrm{mg}$ ) ince tabaka kromatogramları ise 
Krom.3 ve Krom.4'de görülmektedir. Kromatogramlarda $\mathrm{Rf}_{1}: 0.20$ ve $\mathrm{Rf}_{2}$ : $0.36^{\prime} \mathrm{da}$ olmak üzere 2 alkamin lekesi görülmüştür. 3 ve 4 numaralı lekeler ise sarı renkte görülen sapogenol lekeleridir.

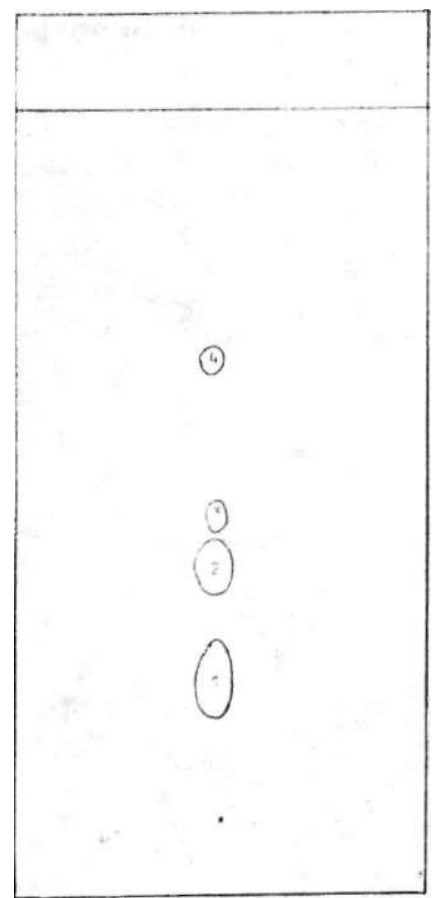

Krom. 3: Alkaminin ince tabaka kromatogramı

Belirteç: Kaegi-Miescher

1 ve 2: alkamin (mavi)

3 ve 4: sapogenol (sarı)

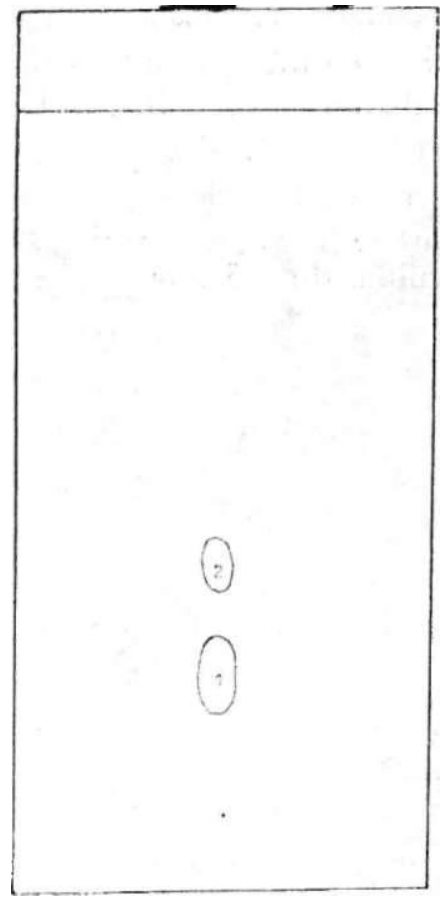

Krom. 4: Alkaminin ince tabaka kromatogramı

Belirteç: \% $50 \quad \mathrm{H}_{1} \mathrm{SO}$

1: alkamin (erguvan)

2: alkamin-dien (koyu erguvan)

Yapıları çok yakın olan alkaminler ile $80^{\circ}-300^{\circ} \mathrm{C}$ ler arasında karakteristik renkler veren $\mathrm{H}_{2} \mathrm{SO}_{4}$ belirteci kullanılmasi sonucunda ince tabaka plağında oluşan renkler incelendiğinde, alkamin lekelerinin renginin sadece solasodin'in rengine uyduğu gözlenmiştir. 110 saniyede ve $105^{\circ} \mathrm{C}$ de ortaya çıkan pembe renk ( $\left.R f_{1}: 0.20\right)$, sıcaklığın arttırılması ile erguvan rengine dönüşmüştür. $\mathrm{Rf}_{2}: 0.36$ daki daha koyu erguvan renkteki leke, S.dulcamardda bulunması mümkün olan 
tomatidenol ve soladulsidin alkaminlerinin renk testine uymadı̆̆ından, glukoalkaloitlerin hidrolizi sırasında bir hidroliz ürünü olan "dien" oluştuğu ve "dien'lerin" daha büyük Rf değerine sahip olduğu bilindiğinden $(2,10)$ Rf: 0.36 daki lekenin ayrı bir alkamin olmayıp, hidroliz ürünü olan bir "dien" olduğu sonucuna varıldı.

Sapogenol lekeleri de görülen alkaminin saflaştırılmasıyla elde edilen kristaller ince tabaka plağında standart solasodin ile karşılaştırıldı̆̆ında; elde edilen kristallerin tek leke verdiği, bu lekenin standart ile aynı Rfdeğerine sahip olduğu $\left(25^{\circ} \mathrm{C} \mathrm{Rf}: 0,60\right)$, Kaegi-Mieseher belirteci ile sapogenol ve "dien" içermediği ve sülfürik asit belirteci ile yapılan renk testine de standart ile aynı cevabı verdiği görülmüştür (Krom.5).

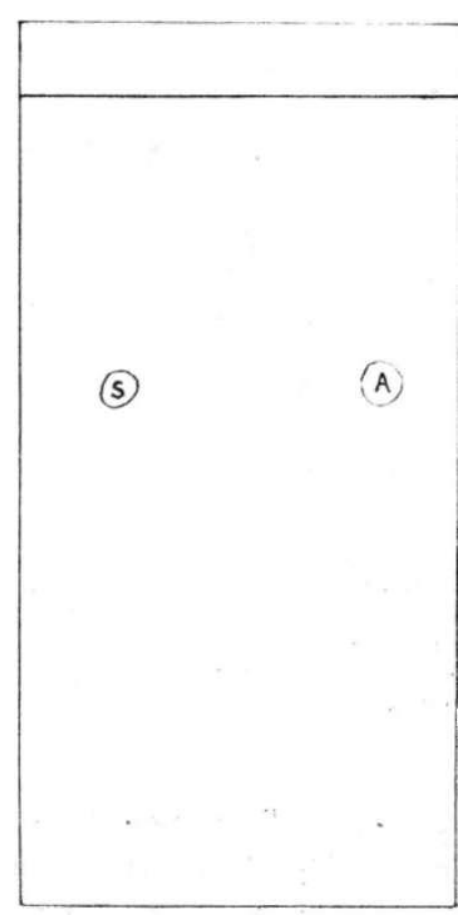

Krom. 5: Alkaminin İTK da standart solasodin ile karşılaştırılması Belirteç: Kaegi-Miescher Sicaklik: $25^{\circ} \mathrm{C}$

S : Standart solasodin

A : Alkamin 
Bu sonuçlara göre bitkisel materyalde bulunan 2 glukoalkaloidin aynı alkaminden türedikleri anlaşılmıştır.

Literatür verilerine göre solasodin için saptanan ergime noktalar1: $197-198^{\circ} \mathrm{C}, 201^{\circ} \mathrm{C}, 198-200^{\circ} \mathrm{C} \operatorname{dir}(10,17,25)$.

Materyalden elde edilen saf alkamin için bulunan değer (E.N.: $\left.199-200^{\circ} \mathrm{C}\right)$ literatür verilerine uymaktadir.

Alkaminin spektral yöntemlerle analizi sonucu spektrumlarda saptanan değerler aşağıda verilmiştir;

IR spektrumu (KBr): 10.3, 10.4, 11.2, $11.5 \mu$ da oksoazospiran bantlar (Spektr. 1).

Kütle spektrumu: m/e 114, 138, 385, 398, 413 de maksimum pikler (Spektr.2)

UV spektrumu ( $\left.\mathrm{CH}_{3} \mathrm{OH}\right): \lambda$ maks. 208 ve 228 (Spektr.3).

Bulunan değerler literatür verilerine ve standart solasodin'in verdiği değerlere uymaktadır. Bu sonuçlar izole edilen alkaloidin solasodin olduğunu ortaya koymuştur.

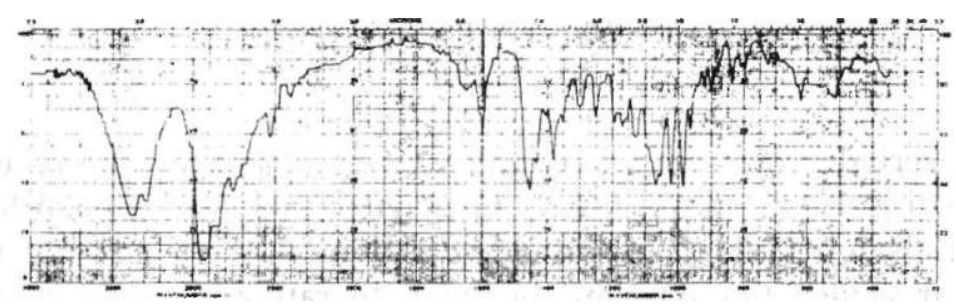

Spektr.: 1 Alkaminin IR spektrumu

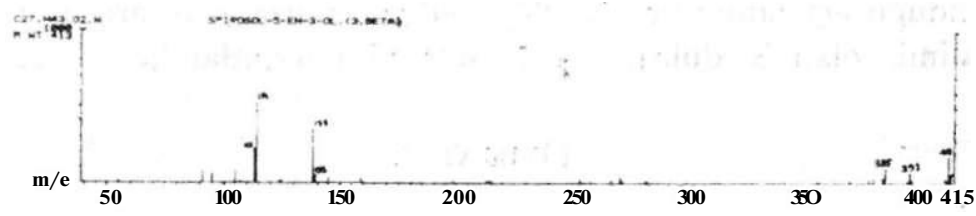

Spektr.: 2 Alkaminin kütle spektrumu 